\title{
FUNCTIONAL AND STRUCTURE OUTCOME INTRAVITREAL BEVACIZUMAB IN DIABETIC RETINOPATHY WITH CLINICALLY SIGNIFICANT MACULAR EDEMA AT BALI MANDARA EYE HOSPITAL
}

Ni Luh Diah Pantjawati ${ }^{1}$, I Ketut Semara Budiyasa ${ }^{1}$, Anak Agung Dewi Adnya Swari ${ }^{1}$, Thedius Watu ${ }^{2}$

${ }^{1}$ Department of Opthalmology, Bali Mandara Eye Hospital

${ }^{2}$ Department of Opthalmology, Udayana University, Sanglah Hospital Bali

\begin{abstract}
Introduction: The increase in diabetics has an impact incidence of diabetic retinopathy and Diabetic Macular Edema (DME). DME due to changes in the blood retinal barrier (BRB), causes fluid accumulation in the macula. This study aims to evaluate the functional outcome visual acuity and structure with optical coherence tomography (OCT) intravitreal bevacizumab (IVB) injection in DME with Clinically Significant Macular Edema (CSME).
\end{abstract}

Methods: This study is a retrospective descriptive and conducted in the Department of Ophthalmology, Bali Mandara Eye Hospital, Denpasar. Data were obtained from the medical records of all diabetic retinopathy patients with clinically significant macular edema who treated with IVB at Bali Mandara Eye Hospital in Denpasar January - December 2018.

Result: Of the 52 subjects, improvement in best corrected visual acuity (BCVA) occurred in 26 (50.0\%) at the first month, 21 (40.4\%) at the third month, and 10 (19.2\%) at the sixth month evaluation. OCT decreased in 44 (84.6\%) at the first month, 16 (30.8\%) at the third month, and 14 (26.9\%) at the sixth month evaluation.

Conclusion: There are visual acuity improvement and central macular thickness reduction at 6 months after IVB injection.

Keywords: Diabetic Retinopathy, Macular edema, Intravitreal Bevacizumab Injection, Anti-VEGF Intravitreal Injection

Cite This Article: SWARI, Dewi Adnya; PANTJAWATI, Ni Luh Diah. Functional and Structure Outcome Intravitreal Bevacizumab in Diabetic Retinopatic with Clinically Significant Macular Edema at Bali Mandara Eye Hospital. International Journal of Retina, [S.I.], v. 3, n. 2, sep. 2020. ISSN 2614-8536. Available at: https://www.ijretina.com/index.php/ijretina/article/view/110

\section{INTRODUCTION}

The prevalence of diabetes is increasing every

*Correspondence to: Anak Agung Dewi Adnya Swari, Department of Ophthalmology Bali Mandara Eye Hospital, dewiadnya@gmail.com year. The Wisconsin Epidemiologic Study of Diabetic Retinopathy reports that $20 \%$ of patients with type I diabetes and $25 \%$ of patients with type Il diabetes will suffer from Diabetic Macula Edema (DME) after 10 years of follow-up. While the incidence of Clinically Significant Macular Edema (CSME) after 4 years of follow-up was $4.3 \%$ in patients with type I diabetes, $5.1 \%$ in type II diabetes with insulin, and $1.3 \%$ in type II diabetes non-therapy insulin. ${ }^{1}$
Intraretinal fluid accumulation over a short period of time, causes decrease of vision is significantly reversible. DME changes in the Blood Retinal Barrier (BRB), causes fluid accumulation in the macula. ${ }^{2}$

The standard management for DME was laser photocoagulation, but there were reports that complications arising from the therapy, an increase in vision and intraocular pressure that was less significant. ${ }^{2}$ 
Therapy with anti-Vascular Endothelial Growth Factor (anti-VEGF) is proposed to be a first-line of DME therapy. ${ }^{3} \quad$ Intravitreal Bevacizumab (IVB) provides stability and increased Visual Acuity (VA), Central Macular Thickness (CMT), and restoring damaged macular anatomy with Fluorescein Angiography (FA) in DME. IVB shown a similar favorable response to macular thickness and IVB prevents exacerbation of macular edema in patients with CSME. ${ }^{4}$ This study aims to evaluate the VA and structure of macula with IVB in CSME by following a guidelines from the Diabetic Retinopathy Clinical Research Network (DRCR.net) with accommodating the local demographic condition such as type 2 diabetes mellitus profiles in Bali.

\section{METHODS}

The research is a retrospective descriptive study. This study aims to look for structural and functional outcomes of bevacizumab anti-VEGF therapy in CSME patients at Bali Mandara Hospital in 2018. This research was conducted at the Vitroretinal Polyclinic of Bali Mandara Eye Hospital, Denpasar in January to April 2020 with data collection patients in January to December 2018.

The research was selected by consecutive sampling from an affordable population. The inclusion were those aged over 18 years, with type two diabetes mellitus who were diagnosed with CSME and were given bevacizumab anti-VEGF therapy every visit per month for 6 months. Informed consent were obtained from all subjects. Exclusion criteria were: 1) patients with other retinal pathologies; 2 ) fundus image quality is not good or patients with incomplete medical records; 3 ) patients get a combination therapy; 4) Patients do not come for control at least once time.

The operational definition is CSME diagnoses are based on Optical Coherence Tomography (OCT) gold standard examination by an ophthalmologist Bali Mandara Hospital as recorded in the medical record and patient characteristics consist of gender and age. Data regarding sex and age recorded in the medical record; the duration of suffering from diabetes mellitus is the length of time the patient has diabetes mellitus; frequency of bevacizumab anti-VEGF injection: judged by the number of times the patient took bevacizumab anti-VEGF injection during a year; functional output IVB anti-VEGF therapy: assessed from BCVA, which is the best visual acuity possible for patients with lens correction and measured with snellen charts in one eye, $B C V A$ records at the before therapy, $3^{\text {rd }}$ month, and $6^{\text {th }}$ month; structural outcomes of IVB anti-VEGF therapy were assessed from the CMT, which is the average thickness of the retina obtained from OCT measurements, recorded before surgery, at the $3^{\text {rd }}$ and $6^{\text {th }}$ months therapy.

\section{RESULTS}

Characteristics of research subjects in this study with sample criteria recorded in the medical record report of 52 subjects. Based on the data on demographic characteristics in this study, male was more than female (59.6\% compared to $40.4 \%$ ).

Table 1. Demographic Characteristics of Subjects

\begin{tabular}{ll}
\hline Characteristics & $\begin{array}{l}\text { Intravitreal } \\
\text { Injection }(\mathrm{n}=52)\end{array}$ \\
\hline Age ( median year) & 60,58 \\
\hline Male & $31(59.6 \%)$ \\
\hline Female & $21(40.4 \%)$ \\
\hline Duration of DM & $24(46.2 \%)$ \\
\hline$>5$ years & $28(53.8 \%)$ \\
\hline$<5$ years & 2,15 \\
\hline Injection frequency & \\
\hline & The demographic characteristics of the study \\
subjects are summarized in table 1. Mean age 60,58 years \\
old. The prevalence was higher on duration of DM < 5 \\
years rather than $>5$ years. The mean frequency of IVB \\
injection was 2,15.
\end{tabular}

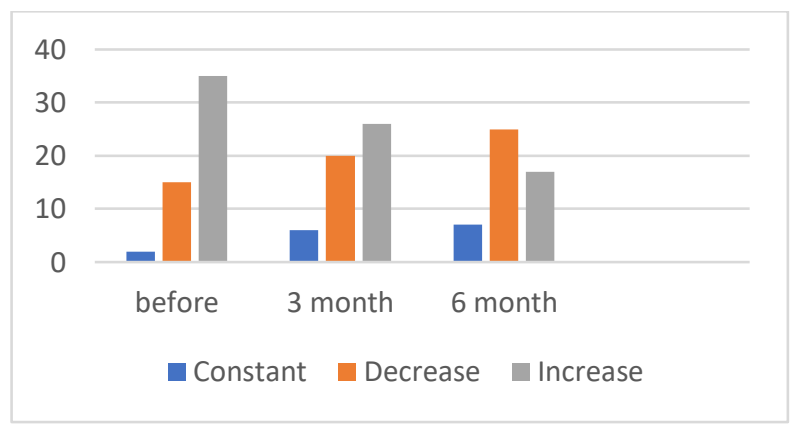

Figure 1. BCVA before, 3 months, 6 months post IVB

In Figure 1, it can be seen that after IVB, the BCVA increases in the $3^{\text {st }}$ month and $6^{\text {th }}$ month. The average result of the VA before surgery was 0.40 LogMar, the $3^{\text {rd }}$ months 0.30 LogMar and the $6^{\text {th }}$ months 0.18 LogMar.

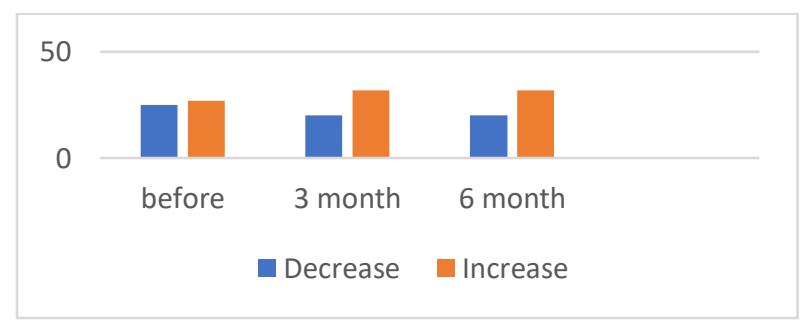

Figure 2. CMT before IVB, 3 months, and 6 months post IVB 
Decreased in CMT occurred in most of the cases on month 3 and month 6 .

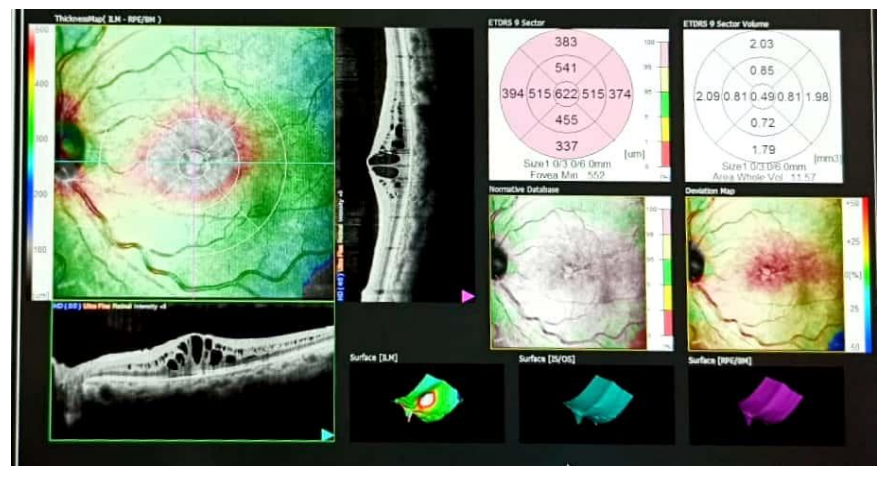

Figure 3. OCT before IVB

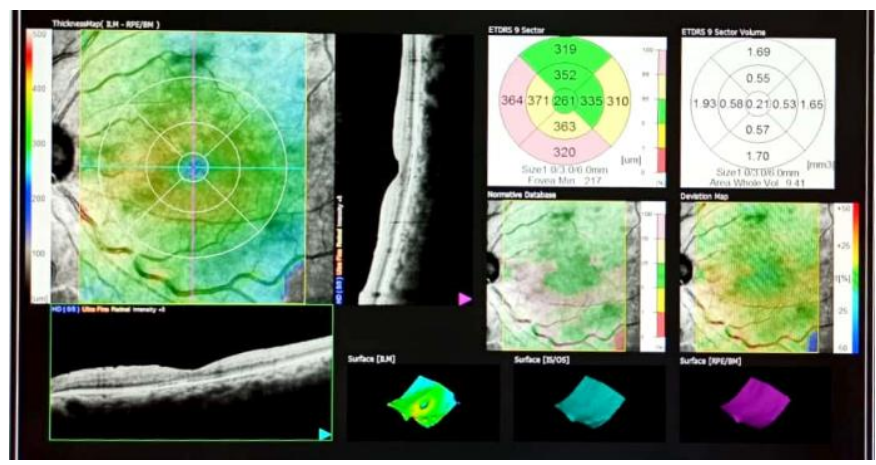

Figure 4. OCT after 6 months IVB

In Figure 3, it can be seen that OCT one of the subjects before IVB, CMT was $622 \mu \mathrm{m}$ and CMT after 6 months IVB became $261 \mu \mathrm{m}$ (Figure 4). There was a decrease in CMT with DME by OCT after IVB.

\section{DISCUSSION}

Intravitreal Bevacizumab minimizes the risk of exudative complications, development of retinal neovascularization, vitreous bleeding, and decreased vision caused by macular edema. IVB provides stability and increased VA and OCT in diabetes macular edema.

In this study, male gender as many as 31 respondents (59.6\%) and women as many as 21 respondents (40.4\%). Research in Iran, in 28 patients with diabetic macular edema given bevacizumab injections, there were 17 men (60.7\%) and 11 women (39.3\%). ${ }^{5}$ There is no research that explains exactly why IVB injection is more often in male patients, but is thought to risk factors for retinal vascular disease, hypertension and smoking.

Age distribution with a mean value of 60.58 . The same thing was obtained in 8 institutions in Latin America obtained from 1173 patients who underwent bevacizumab injections with an average age of 54 years. ${ }^{6}$
This is probably caused by the most common underlying disease that causes patients to undergo IVB injection is diabetic retinopathy, AMD, Central Retinal Vein Occlusion (CRVO), where these diseases usually occur at the age of the $5^{\text {th }}$ decade. ${ }^{7}$ One of the risk factors for worsening of these basic diseases is aging. ${ }^{8}$

The duration of diabetes mellitus is categorized into 2 categories, duration under 5 years and more than 5 years. Duration under 5 years was $24(46.2 \%)$ and more than 5 years was 28 (53.8\%). Research conducted by Prakash and Kothari (2016) that the duration of diabetes more than 5 years is significantly related to the incidence of CSME. ${ }^{9}$

Research Wu et al ${ }^{6}$ got an average number of injections per eye is 3.3 injections (range 1-10 injections). Research by Marticorena et al found that the total number of injections per eye in patients was 1.8 injections. ${ }^{10}$ The amount of bevacizumab injection is usually based on the clinical condition of the affected eye, re-injection is carried out in cases that show recurrence. The short halflife of bevacizumab also causes the need for re-injection to maintain its effect. The average time for retinal neovascular recurrence after anti-VEGF administration varies from 2 weeks to 3 months. ${ }^{11}$

Research conducted by Khan et $\mathrm{al}^{10}$ in patients with diabetic macular edema also obtained sharp improvement of vision on the logMAR scale after IVB injection from 0.726 before injection to 0.515 at one week post injection, to 0.461 at one month post injection and becoming 0.452 in the third month post injection. This study found that there was a sharp improvement in vision in patients undergoing IVB injection. IVB injection has been shown to significantly improve sharp vision and also reduce macular edema. Bevacizumab has the ability to reduce VEGF secretion, improve the integrity of the retinal blood barrier, cause local vasoconstriction (antiedema), reduce inflammatory reactions, reduce vascular leakage (angiostatic) and cause regression of neovascularization. ${ }^{11,12}$

Intravitreal administration of Bevacizumab injection has been shown to improvement a vision and anatomically reduce the thickness of the central retina. ${ }^{13}$ Other research results according to S.A Mehany et al, who reported a mean macular thickness of $455 \mu \mathrm{m} \pm 126$ decreased to $356 \mu \mathrm{m} \pm 118$ after one month follow-up ( $P$ $<0.02)^{14}$ 
Bevacizumab is an Anti-VEGF injection that is useful in the treatment of macular edema, where repeated injections are very well tolerated by the retina. According to Rosenfeld et al first reported a decrease in retinal thickness in macular edema measured using OCT after administration of bevacizumab therapy. ${ }^{15}$

The distribution of IVB frequency in CSME obtained the lowest result 1 time, the highest result 5 times, with average value of 2.15. Research Wu et al, get an average number of injections per eye is 3.3 injections (range 1-10 injections) and research by Marticorena et al, found that the total number of injections per eye in patients was 1.8 injections. This study found that the median number of injections in each eye was 1 injection with a range of 1-3 injections in each eye. ${ }^{6}$ The amount of bevacizumab injection is usually based on the clinical condition of the affected eye, re-injection is carried out in cases that show recurrence. The short half-life of bevacizumab also causes the need for re-injection to maintain its effect. The average time for retinal neovascular recurrence after antiVEGF administration varies from 2 weeks to 3 months. ${ }^{6}$

\section{CONCLUSION}

Functional outcomes by recording BCVA shown significant improvement in VA and structural outcomes by recording the results of measurements CMT of OCT proved that IVB injection reduced retinal thickness in patients of CSME.

\section{REFERENCES}

1. Klein R, Klein BE, Moss SE, Davis MD, DeMets DL. 1984. The Wisconsin epidemiologic study of diabetic retinopathy. IV. Diabetic macular edema. Ophthalmology; 91: 1464-1474.

2. Fu YD, Wang $P$, Meng $X X$, et al. 2017. Structural and functional assessment after intravitreal injection of ranibizumab in diabetic macular edema. Doc opthalmol. DOI 10.1007/s10633-017-9604-z.

3. Nguyen QD, Brown DM, Marcus DM, Boyer DS, Patel S, Feiner L, Gibson A, Sy J, Rundle AC, Hopkins JJ, Rubio RG, Ehrlich JS, Rise, Ride Research Group. Ranibizumab for diabetic macular edema: results from 2 phase III randomized trials: RISE and RIDE. 2012. Ophthalmology. 119(4):789- 801.

4. Arevalo JK, Wu L, Sanchez JG, et al. Intravitreal bevacizumab (avastin) for proliferative diabetic retinopathy: 6-months follow-up. 2009. Eye.23(1): 117- 123.

5. Razmju IJP, Afarid M, Sarvestani AS, et al. Intravitreal injection of Bevacizumab: Review of our previous experience. 2018. Iranian Journal of Pharmaceutical Research. 17(3): 1093-1098. PMID: 30127831. PMCID: PMC6094424.

6. Wu L, Maria A, Mercado $H Q$, et al. Twelve-month safety of intravitreal injections of bevacizumab (Avastin): results of the Pan-American Collaborative Retina Study Group (PACORES). 2008. Albrecht von Graæes Archiv für Ophthalmologie 246(1):81-7. DOI: $10.1007 / \mathrm{s} 00417-007-0660-z$.

7. American Academy of Opthalmology. Retina and Vitreous. Basic and clinical science course. Section 12. 2017-2018. San Fransisco: AAO

8. Arevalo JK. Diabetic macular edema: Current management 2013. 2013. World Journal of Diabetes.4(6): $\quad$ 231-233. PMID: 24379911. PMCID: PMC3874480

9. Jaissle GB, Szurman P, Feltgen N, et al. Predictive factors for functional improvement after intravitreal bevacizumab therapy for macular edema due to branch retinal vein occlusion. 2011. Graefes Arch Clin Exp Ophthalmol 249:183-192. Doi: 10.1007/s00417010-1470-2.

10. Pikkel J, Chassid O, Busool Y, et al. Bevacizumab for CRVO associated cme: effect of timing and frequency of injections on final visual outcome.2013. Journal of Ophthalmology Vol 2013: 1-4: 974670. PMID: 24490054. PMCID: PMC3893752.

11. Khan A, Choudhry AA, Siddiq Z, et al. Intravitreal bevacizumab for treatment diabetic macular edema. 2012. Pak J Ophthalmol Vol 28 (1): 3-9.

12. Kimoto K, and Kubota T. Anti-VEGF agents for ocular angiogenesis and vascular permeability. 2012. Journal of Ophthalmology 1-11. Doi: 10.1155/2012/852183.

13. Arevalo JF. Intravitreal bevacizumab as anti-vasscular endothelial growth factor in the managemen of complications of proliferative diabetic retinopathy. 2013. Medical Hypothesis, Discovery and Innovation Ophthalmology Journal Vol 2(1): 20-24. PMID: 24600636. PMCID: PMC3939761

14. Mehany SA, Mourad KM, Ahmad M, et al. Early Avastin management in acute retinal vein occlusion. 
2010. Saudi Journal of ophthalmology 24,87:94. Doi: 10.1016/j.sjopt.2010.03.004.

15. Rehak J, Rehak M. 2008. Mini review branch retinal vein occlusion: pathogenesis, visual prognosis, and treatment modalities. Heathcare 33:111-131. Doi: 10.1080/02713680701851902.

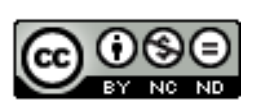

This work licensed under Creative Commons Attribution 